\title{
Editorial
}

\section{Instructions to authors as a support to elaborate and submit an article}

\author{
Eduardo de Paula Vieira1, Juliana Gonçalves Reis² \\ ${ }^{1}$ Editor in chief. ${ }^{2}$ Executive editor
}

Vieira EP, Reis JC. Instructions to authors as a support to elaborate and submit an article. J Coloproctol, 2012;32(3): 207.

We have initiated many changes in Revista Brasileira de Coloproctologia. For instance, we have changed the title to Journal of Coloproctology (JCOL) and now the publication is in English. The aim of these changes is to turn a regional journal into an international one.

Such challenge has led us to update the goals, the editorial policy, the guidelines of the journal, as well as to create new flows for the publication processes.

Instructions to authors have been redefined, characterizing the new moment of JCOL. Its main goals are: to provide guidance for the rules adopted by the journal, to prepare the manuscript for submission, to improve the quality of scientific production and to speed up the process of publication.

From these new guidelines, the categories of accepted articles or type of contribution for the publication were established, as well as adopted languages, ethical considerations, requirements of originality and uniqueness, type of peer review, process of article evaluation, copyright transfer, online submission, criteria for authorship, format, style and limits of the manuscripts. The relevance of paying attention to the guidelines of the journal while elaborating the article is to maximize the visibility of your research.

A carefull reading of the instructions can improve the quality of the scientific production, assisting the journal acceptance. Furthermore, it can make the identification and the recovery of the article easier in bibliographic databases. It can also stimulate the metric accuracy of the article and the journal.

Thus, we emphasize that the instructions to authors should serve as a support in the elaboration and submission of the article. Neglecting the guidelines of the journal may cause a delay on the publication process, and increase the cost of the article to the journal, or even lead to its refusal. These implications can influence on the development of the coloproctology as a field of knowledge.

Palavras-chave: scientific communication; scientific publishing; instructions for authors.

Correspondence to:

Juliana Gonçalves Reis

julianareis20@yahoo.com.br 